\title{
ASSESSMENT OF GASTRIC TUMOURS HIGHLIGHTING GASTROINTESTINAL STROMAL TUMOURS (GIST)- A STUDY OF 75 CASES
}

\author{
Pratyusha Bhattacharjee ${ }^{1}$, Himansu Roy², Saumik Chakraborty 3 \\ ${ }_{1}^{1}$ Specialist Medical Officer, Department of Pathology, Siliguri District Hospital, Darjeeling, West Bengal. \\ ${ }^{2}$ Associate Professor, Department of Surgery, Medical College, Kolkata, West Bengal. \\ ${ }^{3}$ Specialist Medical Officer, Department of Community Medicine, North Bengal Medical College and Hospital, Darjeeling, West Bengal.
}

\section{ABSTRACT}

\section{BACKGROUND}

Accurate diagnosis of gastric neoplasm is challenging and demands thorough histopathological evaluation. This study laid emphasis on GIST cases and their pattern of immunoreactivity with CD-117 and DOG-1, as on many occasions they are misdiagnosed.

Aims and Objectives- To study histopathological features of various gastric tumours and compare the pattern of immunoreactivity of GIST cases with CD-117 vis-a-vis DOG-1.

\section{MATERIALS AND METHODS}

A study of patients with gastric tumours was conducted in a tertiary care hospital including careful examination of haematoxylin and eosin stained sections. Immunohistochemistry was performed for markers DOG-1 and CD-117 in cases diagnosed as GIST.

Statistical analysis used- Tables and diagrams depicting data were prepared and analysed using SPSS version 20.0. Categorical variables were expressed as number of patients and percentage of patients and compared using Pearson's Chi-Square test for independence of attributes. An alpha level of $5 \%$ has been taken, i.e. if any p-value is less than 0.05 it has been considered as significant.

Settings and Design- It was a descriptive type of study, conducted for a period of two years.

\section{RESULTS}

Gastric tumours are common in age group of 51 - 60 years and in males. Among 75 cases, 54 cases were located at body of stomach. Predominantly, ulcerative growth pattern was observed. 16 cases were suspected to be GIST histopathologically, 44 moderately differentiated adenocarcinoma, 1 poorly differentiated neuroendocrine carcinoma, 5 infiltrating poorly differentiated adenocarcinoma and 9 well differentiated adenocarcinoma. Mostly advanced stage, pT2N1Mx (42.6\%) cases were detected. 16 cases were differentially diagnosed as GIST.

\section{CONCLUSION}

Accurate diagnosis of gastric tumours demands thorough histopathological evaluation. DOG-1 has overall superior and crisply localised staining pattern than CD-117.

\section{KEY WORDS}

Gastric Tumours, CD-117, DOG-1.

HOW TO CITE THIS ARTICLE: Bhattacharjee P, Roy H, Chakraborty S. Assessment of gastric tumours highlighting gastrointestinal stromal tumours (GIST)- a study of 75 cases. J. Evolution Med. Dent. Sci. 2018;7(19):2355-2359, DOI: 10.14260/jemds/2018/531

\section{BACKGROUND}

Histopathology of gastric neoplasms are often challenging, and must be thoroughly evaluated to ascertain an accurate diagnosis regarding the type and aggressiveness of the tumours. In this study emphasis was laid on cases of Gastrointestinal Stromal Tumours (GIST), as on many occasions they are misdiagnosed as gastrointestinal leiomyomas, leiomyosarcomas, neurofibromas or schwannomas. Although, CD-117 is generally used as the key diagnostic immunohistochemical (IHC) marker for GIST, a tumour that possess wide spectrum of biologic potential at all sites of their occurrence, yet $4 \%-15 \%$ of GISTs are CD-117

'Financial or Other Competing Interest': None.

Submission 25-03-2018, Peer Review 18-04-2018,

Acceptance 24-04-2018, Published 07-05-2018.

Corresponding Author:

Dr. Himansu Roy,

14/2, Naskar Para Lane,

Flat $A / 3$, P. O. Botanic Garden,

Howrah-711103, West Bengal.

E-mail: dr_hroy007@yahoo.co.in

DOI: $10.14260 / j e m d s / 2018 / 531$

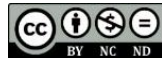

negative or weakly positive.[1,2,3,4] It has been found that DOG1 protein is selectively expressed in GISTs, its gene is localised on chromosome 11 (11q13).[5,6] It has a high rate of protein expression $(94 \%-96 \%)$ in cells of GIST, but usually not found to be expressed in other tissues. ${ }^{[7,8,9]}$ This study was aimed to thoroughly evaluate histopathological features of various gastric tumours and also to compare the pattern of immunoreactivity of GIST cases with CD-117 vis-a-vis DOG-1.

\section{MATERIALS AND METHODS}

The study of patients with gastric tumours attending a tertiary care hospital was conducted in the Department of Pathology in collaboration with Department of Surgery for a period of two years (September 2014 to August 2016). It was a descriptive type of study.

A total of 75 cases were studied. A detailed clinical history with investigations was collected from each patient using a proper data collection form. Approval from ethics committee was taken, consent from all the patients or guardian of the patient was taken, confidentiality of the findings of the patients was ensured and data was utilised purely for academic purpose. 
After step-wise grossing, tissue processing, embedding, blocking and microtomy, haematoxylin and eosin ( $\mathrm{H}$ and $\mathrm{E}$ ) stained sections were prepared for light microscopic examination in each case.

Immunohistochemistry using DAKO rabbit monoclonal antibody kit by peroxidase-antiperoxidase technique was performed for markers DOG-1 and CD-117 in cases diagnosed as GIST on light microscopy. Antigen retrieval was done using a domestic pressure cooker of 2 litres size filled with one litre of TRIS/EDTA buffer (pH 9.0). The slide cradle with Poly-LLysine coated slide bearing the representative section was dipped in this solution. The pressure cooker was removed from heat after 1st whistle and kept under tap water for 30 to 45 mins, i.e. till it reached room temperature. The slides were incubated with primary antibody for 45 minutes to 1 hour in a humid chamber at room temperature. The slides were counterstained with Harris Haematoxylin for 45 seconds followed by dehydration using ascending grades of alcohol, clearing in xylene and mounting with DPX. Categorical variables were expressed as number of patients and percentage of patients and compared using Pearson's Chisquare test for independence of attributes. The statistical software SPSS version 20.0 has been used for the analysis. An alpha level of $5 \%$ has been taken, i.e. if any p-value is less than 0.05 it has been considered as significant.

\section{RESULTS}

A total of 75 cases were studied during the study period of two years (from September 2014 to August 2016). The age of the patient ranged from 31 years to 80 years. Gastric tumours were more common in age group of 51 - 60 years $(38.7 \%)$ with a mean age of 57.69 years (Table 1). Gastric tumours are more common in males $(76 \%)$ than females (24\%) (Figure1A). Out of the 75 cases included in our study, 54 cases $(72 \%)$ had gastric tumours located at the body of the stomach (Figure-1B). Gastric neoplasms were commonly an ulcerative growth in gross appearance (50.7\%) (Table 2). Out of 75 cases studied, 6 cases (8\%) were of Epithelioid Cell Variant of GIST (Low Grade), 1 case (1.3\%) was suspected to be Fibromatosis or Spindle Cell Variant of GIST (Low Grade), 5 cases $(6.7 \%)$ were of Infiltrating Poorly Differentiated Adenocarcinoma, 3 cases (4\%) were suspected to be Leiomyoma or Spindle Cell Variant of GIST (Low Grade), 44 cases (54.7\%) were Moderately Differentiated Gastric Adenocarcinoma, 1 case $(1.3 \%)$ was of Poorly Differentiated Neuroendocrine Carcinoma, 2 cases $(2.7 \%)$ were of Spindle Cell Variant of GIST (High Grade- Mitosis > 5/50 Hpf), 4 cases $(5.3 \%)$ were of Spindle Cell Variant of GIST (Low Grade) and 9 cases (12\%) were of well differentiated Gastric Adenocarcinoma.

Among 75 cases studied, 15 cases (20\%) present at pT2N0Mx, 32 cases $(42.6 \%)$ at pT2N1Mx, 5 cases $(6.7 \%)$ at pT2N2M0, 18 cases (24\%) at pT2N2Mx, 1 case $(1.3 \%)$ at pT2N3M0, 2 cases $(2.7 \%)$ at pT3N0Mx and 2 cases $(2.7 \%)$ at pT3N2Mx. Out of the 75 cases studied, 16 were suspected cases of gastrointestinal stromal tumours (GIST) on light microscopy. They were further evaluated by immunohistochemical analysis using markers CD-117 and DOG-1. Out of 16 GIST cases, 10 cases were positive for both CD-117 and DOG-1. 3 cases were negative for both CD-117 and DOG-1. 1 case was positive for CD-117, but negative for DOG-1. 2 cases were negative for CD-117, but positive for
DOG-1. These associations can be corroborated with Table 3 . The p-value was 0.029 (significant).

Various relevant findings of this study have also been depicted through images (Figure 2, 3 and 4).

\begin{tabular}{|c|c|c|c|}
\hline Age in Years & Frequency & Percent & Mean Age \\
\hline $31-40$ & 10 & 13.3 & 38.00 \\
\hline $41-50$ & 22 & 29.3 & 48.36 \\
\hline $51-60$ & 29 & 38.7 & 57.69 \\
\hline $61-70$ & 13 & 17.3 & 61.31 \\
\hline $71-80$ & 1 & 1.3 & 76.00 \\
\hline Total & $\mathbf{7 5}$ & $\mathbf{1 0 0 . 0}$ & $\mathbf{5 3 . 2 0}$ \\
\hline
\end{tabular}

Table 1. Frequency Distribution table showing Distribution of Gastric Tumours among different Age Groups

\begin{tabular}{|c|c|c|}
\hline Gross Appearance & Frequency & Percent \\
\hline Ulcerative & 38 & 50.7 \\
\hline Ulceroproliferative & 21 & 28.0 \\
\hline $\begin{array}{c}\text { Mass extending from mucosa to } \\
\text { serosa, mucosa intact }\end{array}$ & 10 & 13.3 \\
\hline $\begin{array}{c}\text { Mass extending from mucosa to } \\
\text { serosa, mucosa puckered }\end{array}$ & 4 & 5.3 \\
\hline $\begin{array}{c}\text { Mass extending from mucosa to } \\
\text { serosa, mucosa erythematous }\end{array}$ & 2 & 2.7 \\
\hline Total & $\mathbf{7 5}$ & $\mathbf{1 0 0 . 0}$ \\
\hline $\begin{array}{c}\text { Table 2. Frequency Distribution table showing } \\
\text { Distribution of Gastric Tumours according to Gross } \\
\text { Appearance of the Tumours }\end{array}$ \\
\hline \multicolumn{2}{|c}{} \\
\hline
\end{tabular}

\begin{tabular}{|c|c|c|c|c|}
\hline \multicolumn{2}{|c|}{} & \multicolumn{2}{|c|}{ CD-117 } & \multirow{2}{*}{ Total } \\
\cline { 3 - 5 } & \multirow{2}{*}{ Negative } & 3 & 1 & 4 \\
\cline { 3 - 5 } DOG-1 & $60.0 \%$ & $9.1 \%$ & $25.0 \%$ \\
\cline { 3 - 5 } & \multirow{2}{*}{ Positive } & 2 & 10 & 12 \\
\cline { 3 - 5 } & & $40.0 \%$ & $90.9 \%$ & $75.0 \%$ \\
\hline \multicolumn{2}{|c|}{ Total } & 5 & 11 & 16 \\
\cline { 3 - 4 } & $100.0 \%$ & $100.0 \%$ & $100.0 \%$ \\
\hline \multicolumn{2}{|c|}{$\begin{array}{c}\text { Table 3. Cross-Tabulation showing CD-117 - DOG-1 } \\
\text { association in Cases of GIST }\end{array}$} \\
\hline
\end{tabular}

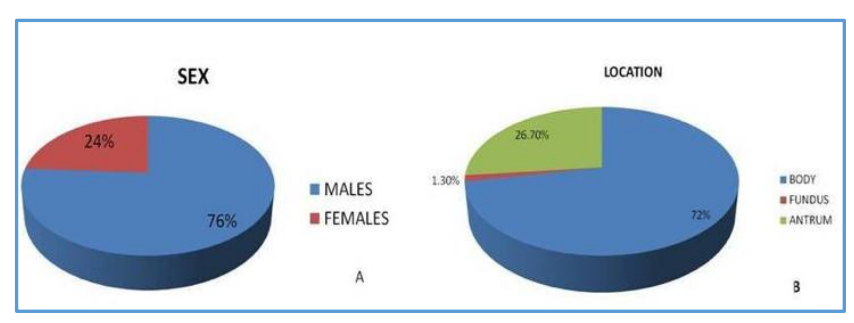

Figure 1. Pie Diagrams

A) Depicting Sex Distribution of Gastric Tumours. B) Depicting Distribution of Gastric Tumours according to Location of the Tumour

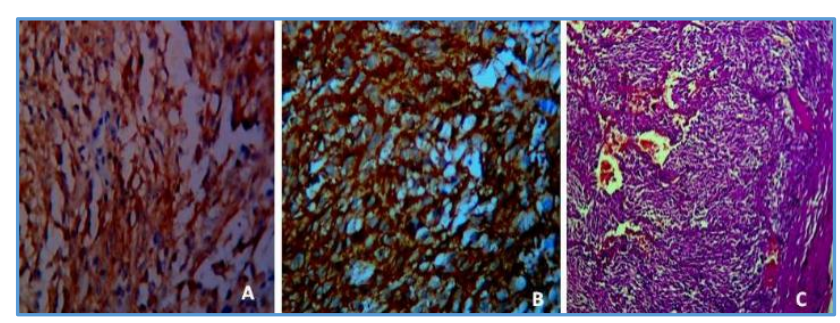

Figure 2. Epithelioid GIST.

A) CD-117 Diffuse Positive (400X).

B) Corresponding DOG-1 Positive (400X).

C) Corresponding H and E Stain (100X) 


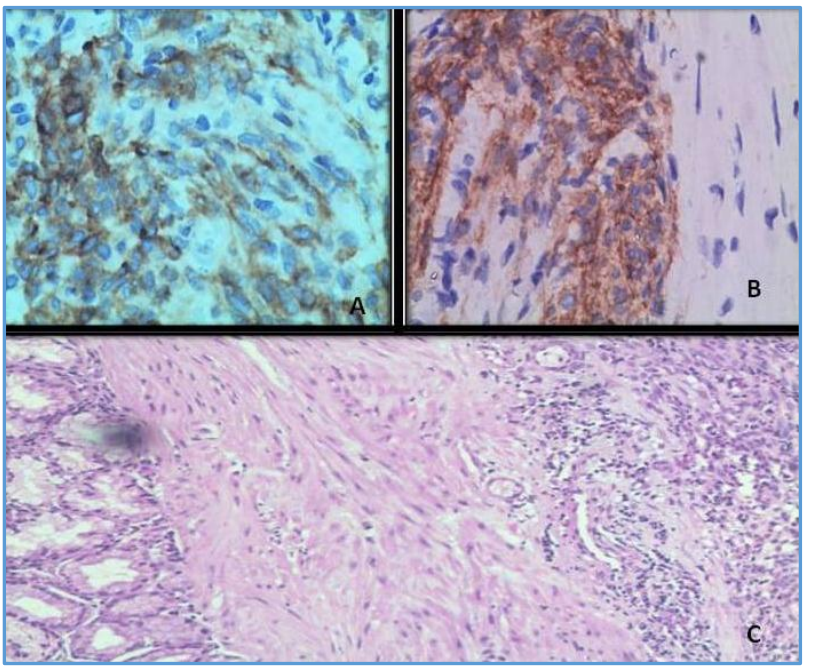

Figure 3. Spindle Cell GIST

A) CD-11 7 Diffuse Positive (400X).

B) Corresponding DOG-1 Positive (400X).

C) Corresponding H and E Stain (100X).

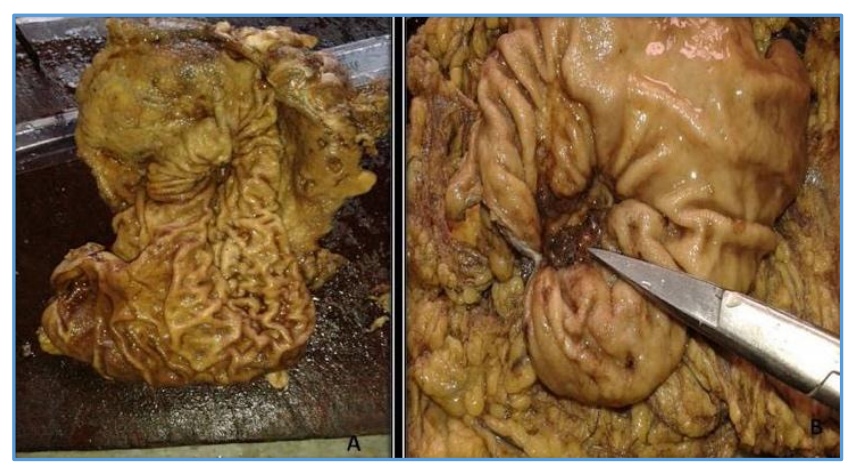

Figure 4. Gross Appearance.

A) Gastric Mass with Mucosa Intact.

B) Ulcerated Growth in Stomach

\section{DISCUSSION}

In this study, gastric tumours were found to be more common in males $(76 \%)$ than females (24\%). Throughout the world, gastric neoplasms are observed to be a disease of the elderly population, predominantly in men.[10,11]

According to this study, gastric tumours were more common in age group of 51 to 60 years (38.7\%). There was a spectrum of median age incidence outlined in various studies conducted in different parts of the world. In the western world, it was 71 years in the USA.[12] In Asian countries, mean ages in different countries were low. For example, in Japan it was 61 years, in Pakistan $48+/-4.47$ years and in Saudi Arabia 47 years. ${ }^{[12,13,14]}$ In this study, the mean age was 57.69 years, which was near similar to the study done in Japan. In Mizoram, male-to-female was 2.3:1,[15] in Saudi Arabia 2.2:1,[13] and in Pakistan 1.5:1.[14] All these show preponderance of gastric neoplasms in elderly male population, which is similar to the findings of our study.

Out of the 75 cases included in the study, 54 cases (72\%) had gastric tumours located at the body of the stomach and they were commonly an ulcerated growth in gross appearance ( $50.7 \%$ cases). In the western world according to various studies, there is progressive increase in proximal stomach cancer and concomitant decline in distal stomach cancer.[16,17] Although, reports from Asian countries were discordant. Japanese and Korean population had preponderance of non-cardia cancer; however, an Iranian study revealed the predominance of cardia cancer.[12] Recently, a report from Kerala in India showed that although predominant site of cancer was antral mucosa, yet the trend was towards proximal shift.[18] Cherian et al revealed no change in site specificity of carcinoma of stomach in South Indian population.[18] Again Qurieshi et al revealed incidences of cancer in proximal, mid and distal stomach to be $42 \%$, $6.2 \%$ and $45.7 \%$ respectively in the Kashmiri population.[19] Afridi et al in their study found growth at cardiac end in 33\%, pylorus and antrum in $40 \%$, linitis plastica in $13.3 \%$ and only body and body and pylorus in $6.7 \%$ of patients. ${ }^{[14]}$ Qurieshi et al reported $35.5 \%$ ulcero-proliferative, $26 \%$ proliferative, $31 \%$ ulcerative and $7.4 \%$ infiltrative lesions during endoscopy performed in Kashmiri patients.[19] Though, in this study, ulcerative growth was the predominant pattern $(50.7 \%)$ followed by ulcero-proliferative pattern of growth (28\%).

In this study, most common histopathological diagnosis was moderately differentiated gastric adenocarcinoma (58.7\%). Similar to this study, Peghini et al showed $88 \%$ of cases with adenocarcinoma and $7 \%$ of cases with lymphoma, thus representing more prevalence of adenocarcinoma than other types of gastric neoplasms.[20] In this study, highest frequency of cases presented at an advanced stage, that is pT2N1Mx (42.6\% cases). Stomach cancers are commonly diagnosed in symptomatic patients with advanced disease.[21] Early asymptomatic tumours are detected predominantly in countries following a screening policy such as Japan.[21]

In this study, 16 cases of gastric tumours which were differentially diagnosed as GISTs or leiomyoma or fibromatosis on light microscopy and were further evaluated by immunohistochemistry by using markers CD-117 and DOG-1. Out of these 16 cases, 10 cases which stained positively for both CD-117 and DOG-1. 2 cases which stained positively for DOG-1, but were negative for CD-117 were considered as GIST; as according to a study by Espinosa et al among GISTs bearing PDGFRA mutations 79\% stained with DOG-1, 9\% with CD-117 and 27\% with CD-34.[5] Review of the literature reveals that about one-third of patients who possess PDGFRA mutations, fail to stain with CD-117.[3] Thus, these 2 cases of GIST may have been misdiagnosed to be cases of leiomyoma. 1 case which was differentially diagnosed as fibromatosis or spindle cell variant of GIST (Low Grade) stained positively for CD-117, but negatively for DOG1 , was finally considered as a case of fibromatosis. Immunohistochemically, CD-117 is the protein product of CKit gene with a rate of protein expression being $80 \%-100 \%$ in GIST, but occasionally expressed in non-GIST cells. ${ }^{[22]}$ Thus, this case would have been misdiagnosed as a case of GIST. There were 3 cases, which were differentially diagnosed to be cases of leiomyoma or spindle cell variant of GIST (Low Grade), stained negatively for both CD-117 and DOG-1. These cases were considered as gastric leiomyoma.

Dei Tos et al observed DOG-1 expression in specimens acquired from 139 GIST patients and 438 non-GIST patients and reported that the sensitivity of DOG-1 expression in assessing GIST was up to $97.84 \%$; concurrently, they also observed positive DOG-1 expression in CD-117- negative patients, recommending that a judicious combination of DOG1 and CD-117 may be more beneficial for diagnosis of 
GIST.[23] However, CD-117 cannot be neglected because of its therapeutic value for administering imatinib. Thus, it is better to use a combination of CD-117 and DOG- 1 for diagnosing the cases of GIST.

In this study, we also observed that overall staining of DOG-1 was superior and crisply localised when compared with the diffuse staining pattern of the CD-117. GISTs have been observed to exhibit diffuse staining with CD-117 at a rate of $65 \%-100 \%$ in various publications. [5,7,24-29]

It was also noticed that staining pattern of DOG-1 was predominantly membranous in the epithelioid variant of GIST.

\section{CONCLUSION}

Accurate diagnosis of gastric tumours demands thorough histopathological evaluation. DOG-1 has overall superior and crisply localised staining pattern than CD-117. Histopathological evaluation of gastric tumours must be done carefully, especially for cases of GIST as they are often misdiagnosed. Use of judicious combination of CD-117 and DOG-1 is recommended for diagnosing cases of GIST, as CD117 has got therapeutic importance for administering imatinib.

\section{REFERENCES}

[1] Miettinen M, Lasota J. Gastrointestinal stromal tumors (GISTs): definition, occurrence, pathology, differential diagnosis and molecular genetics. Pol J Pathol 2003;54(1):3-24.

[2] Miettinen M, Lasota J. Gastrointestinal stromal tumors: review on morphology, molecular pathology, prognosis, and differential diagnosis. Arch Pathol Lab Med 2006;130(10):1466-78.

[3] Hirota S, Isozaki K, Moriyama Y, et al. Gain-of-function mutations of c-kit in human gastrointestinal stromal tumors. Science 1998;279(5350):577-80.

[4] Stomatakos M, Douzinas E, Stefanaki C, et al. Gastrointestinal stromal tumour. World J Surg Oncol 2009;7:61.

[5] Espinosa I, Lee $\mathrm{CH}$, Kim MK, et al. A novel monoclonal antibody against DOG1 is a sensitive and specific marker for gastrointestinal stromal tumours. Am J Surg Pathol 2008;32(2):210-8.

[6] Heinrich MC, Coreless CL, Duensing A, et al. PDGFRA activating mutations in gastrointestinal stromal tumours. Science 2003;299(5607):708-10.

[7] Miettinen M, Wang ZF, Lasota J. DOG1 antibody in the differential diagnosis of gastrointestinal stromal tumors: a study of 1840 cases. Am J Surg Pathol 2009;33(9):1401-8.

[8] Novelli M, Rossi S, Rodriguez-Justo M, et al. DOG1 and CD117 are the antibodies of choice in the diagnosis of gastrointestinal stromal tumours. Histopathology 2010;57(2):259-70.

[9] Liegl B, Hornick JL, Corless CL, et al. Monoclonal antibody DOG-1. 1 shows higher sensitivity than KIT in the diagnosis of gastrointestinal stromal tumors, including unusual subtypes. Am J Surg Pathol 2009;33(3):437-46.

[10] Brenner H, Rothenbacher D, Arndt V. Epidemiology of stomach cancer. Methods Mol Biol 2009;472:467-77.
[11] Yang L. Incidence and mortality of gastric cancer in China. World J Gastroenterol 2006;12(1):17-20.

[12] Julian AA, Timothy CW. Adenocarcinoma and other tumors of the stomach. In: Feldman M, Friedman LS, Brandt LJ, eds. Sleisenger and Fordtrean's Gastrointestinal and Liver Disease. 9th edn. Philadelphia, Pa, USA: Elsevier Saunders 2010.

[13] Satti B, Al-Quorain AA, Al-Gindan YM, et al. Gastric malignancy: clinicopathologic spectrum and relationship to Helicobacter pylori infection. Saudi J Gastroenterol 2005;11(3):149-56.

[14] Afridi SP, Bano F, Shafiq-ur-Rahman. Pattern and presentation of carcinoma stomach. J Coll Physicians Surg Pak 2011;21(3):161-3.

[15] Phukan RK, Zomawia E, Hazarika NC, et al. High prevalence of stomach cancer among the people of Mizoram, India. Current Science 2004;87(3):285-6.

[16] Blot WJ, Devesa SS, Kneller RW, et al. Rising incidence of adenocarcinoma of the esophagus and gastric cardia. JAMA 1991;265(10):1287-9.

[17] Kelley JR, Duggan JM. Gastric cancer epidemiology and risk factors. J Clin Epidemiol 2003;56(1):1-9.

[18] Cherian JV, Sivaraman R, Muthusamy AK, et al. Stomach carcinoma in the Indian subcontinent: a 16year trend. Saudi J Gastroenterol 2007;13(3):114-7.

[19] Qurieshi MA, Masoodi MA, Kadla SA, et al. Gastric cancer in Kashmir. Asian Pac J Cancer Prev 2011;12(1):303-7.

[20] Peghini M, Rajaonarison P, Pecarrere JL, et al. Épidémiologie des cancers du tube digestif à Madagascar: apport de 14000 endoscopies effectuées $\mathrm{au}$ centre hospitalier de Soavinandriana à Antananarivo. Med Afr Noire 1997;44(10):518-21.

[21] Elmajjaoui S, Ismaili N, Zaidi H, et al. Epidemiological, clinical, pathological, and therapeutic aspects of gastric cancer in Morocco. Clinical Cancer Investigation Journal 2014;3(1):3-8.

[22] Liu X, Ma D, Wu L, et al. Expression and clinical significance of $\mathrm{c}$-Kit oncogene in gastointestinal stromal tumors. Zhonghua Wai Ke Za Zhi 2002;40(4):277-9.

[23] Dei Tos AP. The reappraisal of gastrointestinal stromal tumors: from Stout to the KIT revolution. Virchows Arch 2003;442(5):421-8.

[24] Miettinen M, Makhlouf $\mathrm{H}$, Sobin LH, et al. Gastrointestinal stromal tumors of the jejunum and ileum: a clinicopathologic, immunohistochemical, and molecular genetic study of 906 cases before imatinib with long-term follow-up. Am J Surg Pathol 2006;30(4):477-89.

[25] Ardeleanu C, Arsene D, Hinescu M, et al. Pancreatic expression of DOG1: a novel gastrointestinal stromal tumor (GIST) biomarker. Appl Immunohistochem Mol Morphol 2009;17(5):413-8.

[26] Lopes LF, West RB, Bacchi LM, et al. DOG1 for the diagnosis of gastrointestinal stromal tumor (GIST): Comparison between 2 different antibodies. Appl Immunohistochem Mol Morphol 2010;18(4):333-7.

[27] Novelli R, Rossi S, Rodriguez-Justo M, et al. DOG1 and CD117 are the antibodies of choice in the diagnosis of gastrointestinal stromal tumours. Histopathology 2010;57(2):259-70. 


\section{Jemds.com}

[28] Sui XL, Wang H, Sun XW. Expression of DOG1, CD117 and PDGFRA in gastrointestinal stromal tumors and correlations with clinicopathology. Asian Pac J Cancer Prev 2012;13(4):1389-93.
Original Research Article

[29] Kara T, Serinsoz E, Arpaci RB, et al. Contribution of DOG1 expression to the diagnosis of gastrointestinal stromal tumors. Pathol Res Pract 2013;209(7):413-7. 